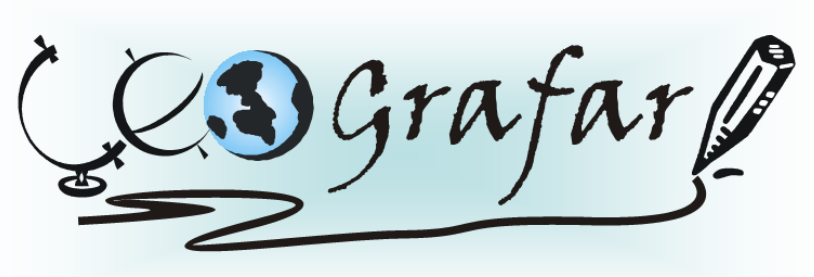

Revista Eletrônica do Programa de Pós-Graduação em Geografia - UFPR

\title{
ESTRUTURA E DISTRIBUIÇÃO ESPACIAL DE MANGUEIRAS (Mangifera indica $L$.) NAS RUAS DA CIDADE DE BELÉM (PA)
}

\section{STRUCTURE AND SPATIAL DISTRIBUTION OF MANGO TREES (Mangifera indica L.) IN THE STREETS OF BELÉM CITY (PA)}

\section{(Recebido em 20.10.2015; Aceito em: 05.02.2016)}

\author{
Dâmaris Araújo da Silva \\ Doutoranda em Engenharia Florestal \\ Universidade Federal do Paraná \\ Curitiba, PR, Brasil \\ e-mail:damarislevita11@yahoo.com.br \\ Daniela Biondi \\ Prof ${ }^{a}$. Dr ${ }^{a}$ do Dep. de Ciências Florestais \\ Universidade Federal do Paraná \\ Curitiba, PR, Brasil \\ e-mail: dbiondi@ufpr.br \\ Antônio Carlos Batista \\ Prof. Dr. do Dep. de Ciências Florestais \\ Universidade Federal do Paraná \\ Curitiba, PR, Brasil \\ e-mail: batistaufpr@gmail.com
}

\section{RESUMO}

O objetivo desta pesquisa foi analisar a estrutura e distribuição espacial dos indivíduos de mangueira no Distrito Administrativo de Belém (DABEL). Foi percorrida toda a malha viária do distrito, $424,45 \mathrm{~km}$, sendo encontrados $36,86 \mathrm{~km}$ de calçadas arborizadas com mangueira (Mangifera indica L.). Foram quantificadas 2.649 mangueiras e calculados os seguintes índices: IMQC (índice de mangueira por quilômetro de calçada), ICAcalç (índice de cobertura arbórea) e IDA (índice de densidade arbórea). A distribuição de altura apresentou curva unimodal, caracterizando a predominância de árvores de grande porte. A distribuição diamétrica demonstrou maior concentração de árvores em estágio maduro. $\mathrm{O}$ maior IMQC foi para o bairro Nazaré e os maiores ICAcalç e IDA foram para o bairro 
Campina. Constatou-se uma má distribuição de mangueiras nas ruas, denotando que essa arborização não possui políticas específicas de manejo.

Palavras-chave: arborização urbana; árvore frutífera; índice de arborização urbana.

\begin{abstract}
The main goal of this research was analyze the structure and spatial distribution of mango trees in the Administrative District of Belém. The all streets of the district was covered, totalizing $425.45 \mathrm{~km}$, and it was found only $36.86 \mathrm{~km}$ of sidewalks wooded with mango trees (Mangifera indica L.). There were quantified 2,649 mango trees and it was calculated the following indices: Index of mango tree per kilometer of sidewalk (IMKS), Index of arboreal coverage (IAC) and Index of arboreal density (IAD). The height's distribution presented a unimodal curve, characterizing a predominance of great trees. The diametric distribution demonstrated the largest concentration of trees in the mature stage. The greatest IMKS was in the Nazare neighborhood and the greatest IAC and IAD were in Campina neighborhood. It was verify an inadequate distribution of mango trees in the streets, indicating that this afforestation does not have specifics policies of management.
\end{abstract}

Keywords: urban arborization; fruit tree; arborization index.

\title{
INTRODUÇÃO
}

Mangifera indica L., conhecida popularmente como mangueira, é uma planta frutífera exótica típica de climas tropicais. Esta espécie pertence a família Anacardiaceae, sendo reconhecidas duas variedades geográficas: uma da índia e outra proveniente das Filipinas e Sudoeste da Ásia ( SILVA, 2000). Destaca-se por apresentar fruto do tipo drupa, que pode pesar de mais de $1 \mathrm{~kg}$. É uma árvore frondosa, perenifólia, que pode atingir até $30 \mathrm{~m}$ de altura. Possui copa globosa, densa com folhas jovens aromáticas, simples e alternas (LORENZI et al., 2006).

$O$ fruto da mangueira se destaca no meio urbano da cidade de Belém, capital paraense, pois, uma parte da população paraense faz da manga uma fonte temporária de renda nas épocas de safra, que geralmente se prolonga entre os meses de dezembro e março, coincidindo com o período chuvoso (LOUREIRO; BARBOSA, 2010). Outro grande benefício oferecido pela mangueira é o destaque ornamental e paisagístico oferecido pelos corredores de mangueiras ao longo das vias de Belém. 
Ao longo da história, a mangueira foi a espécie que mais se destacou por diversas singularidades de adaptação ao ecossistema da região: ser uma árvore clássica dos antepassados, ter rápido crescimento, folhagem densa e beneficiar com uma ampla sombra (ANDRADE, 2003). Segundo o mesmo autor, esta espécie escolhida atendeu perfeitamente a problemática ambiental da cidade da época de seu plantio, ao criar um microclima agradável, paisagem contemplativa e verdejante, bem-estar significativo e formação de túneis verdes nas ruas e avenidas da cidade de Belém.

De acordo com Nascimento et al. (2010), a cidade das mangueiras acabou se transformando em destaque nacional devido os túneis formados pelas mangueiras que podem ser encontradas nos bairros mais centrais da cidade. Além disso, a paisagem tem uma forte influência da característica local, com comunicação com o rio Guajará, oferecendo um destaque paisagístico.

Dessa forma, a mangueira conquistou seu espaço no cenário urbano de Belém, sendo legalmente instituída como patrimônio histórico, conforme a lei no 8909, de 29 de março de 2012, que dispõe sobre o plano municipal de arborização urbana de Belém.

Contudo, Brasil (2013) afirma que existe uma grande necessidade da realização de uma avaliação quali-quantitativa das mangueiras na cidade de Belém, pois há mais de dez anos isto não é realizado. Além disso, grande parte dessas espécies foi plantada numa cidade de Belém muito diferente do que se apresenta agora. Isto provavelmente auxiliaria no planejamento da arborização viária facilitando o monitoramento e manejo das mangueiras.

A compreensão da estrutura da arborização de ruas é pré-requisito para a quantificação de sua função e valor, permitindo o gerenciamento a longo prazo, com redução dos custos de manutenção e aumento dos benefícios, além de servir como base para estimativas do impacto de programas florestais e da vitalidade de uma cidade (MACO; MCPHERSON, 2003).

O objetivo desta pesquisa foi analisar a estrutura e distribuição espacial da mangueira no Distrito Administrativo de Belém. 


\section{MATERIAL E MÉTODO}

A pesquisa foi realizada no Distrito Administrativo de Belém (DABEL), localizado no município de Belém (Figura 1 e 2) e ocupa uma área de $13,7 \mathrm{~km}^{2}$. A capital paraense localiza- se na porção oeste do estado do Pará a uma altitude média de $4 \mathrm{~m}$, sofrendo influência das marés altas e situa-se aproximadamente a $01^{\circ} 27^{\prime}$ de latitude sul e $48^{\circ} 30^{\prime}$ de longitude. Segundo a classificação de Köppen, a cidade de Belém localiza-se em região climática do tipo Afi (quente e úmido), considerado como clima de floresta tropical, permanentemente úmido, com temperatura média anual igual a $25^{\circ} \mathrm{C}$. A precipitação média anual é de $2.834 \mathrm{~mm}$ (INSTITUTO DE DESENVOLVIMENTO ECONÔMICO, SOCIAL E AMBIENTAL DO PARÁ - IDESP, 2013). .

A vegetação compõe-se de florestas secundárias que substituíram a antiga Floresta Densa dos baixos platôs, entremeada por fragmentos de mangues e siriubais, que domina os tratos marginais dos cursos d' água e as baixadas, onde prevalecem formações herbáceas, subarbustivas e arbustivas (IDESP, 2013).

O Distrito Administrativo de Belém (DABEL) limita-se com os distritos de Sacramenta, Entroncamento e Guamá. O distrito é composto pelos seguintes bairros: Reduto, Campina, Nazaré e parte dos bairros do Marco, Umarizal, São Brás, Guamá, Cremação, Batista Campos, Cidade Velha, Jurunas e Canudos (PREFEITURA MUNICIPAL DE BELÉM - PMB, 2012).

Segundo Gusmão (2014), o DABEL engloba os bairros mais nobres da capital paraense, representando a área mais valorizada da cidade devido a concentração de serviços e áreas verdes. Para Luz e Rodrigues (2014), o DABEL é composto pelos bairros pioneiros no processo de arborização, de maior adensamento urbano, concentração de edificações verticais e horizontais, de serviços e possui o maior número de praças.

O Distrito Administrativo de Belém foi selecionado nesta pesquisa por ser a área que apresenta uma urbanização consolidada e concentra os bairros que detém a maioria da arborização com mangueira da cidade de Belém. 


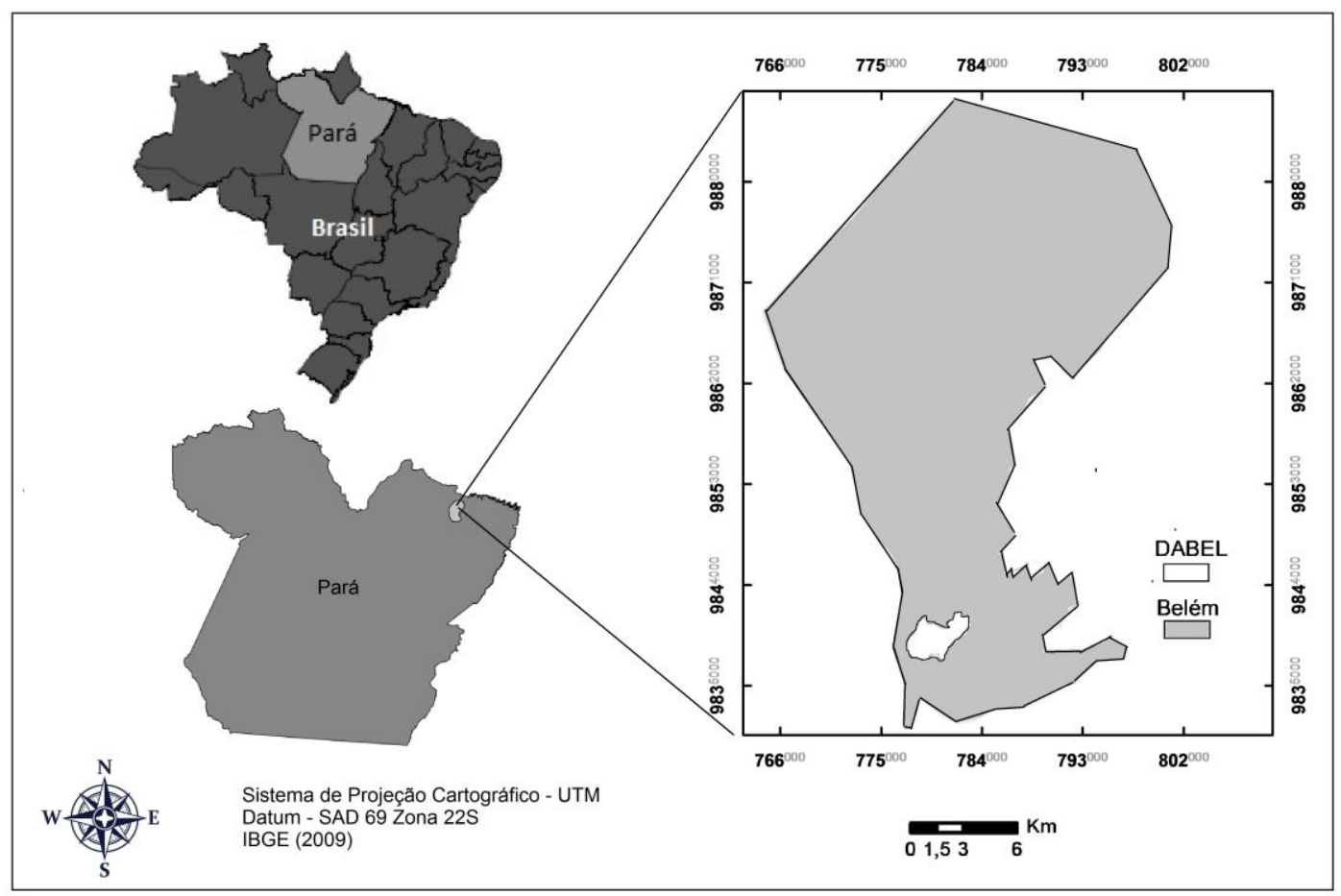

Figura 1 - Localização geográfica da cidade de Belém com destaque para o DABEL.

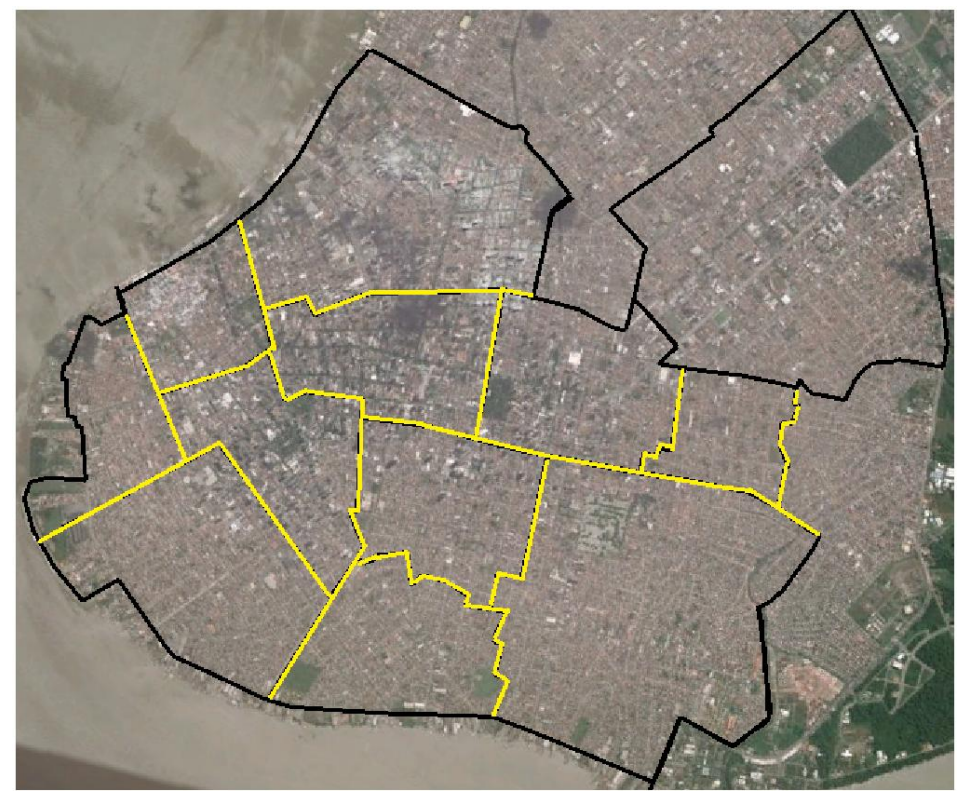

Figura 2 - Localização do DABEL com destaque das principais ruas que compõem o distrito.

O levantamento quantitativo dos indivíduos de mangueira foi do tipo censo e realizado entre os meses de janeiro e fevereiro de 2014. Foram consideradas todas as ruas e mangueiras localizadas nas ruas do DABEL.

As mangueiras foram cadastradas por coordenadas geográficas, fornecidas pelo Google Earth e verificadas em campo. As mangueiras que não eram 
encontradas em campo foram inseridas aos dados fornecidos pelo receptor GPS Garmim® Etrex por meio do programa Quantum GIS 1.8.0. Também se adotou o Sistema de Projeção Geográfica UTM (Universal Transversal de Mercator) e Datum SAD 69, 22 S. Assim, os dados coletados foram importados em formato shapefile (.shp) para o programa Quantum GIS 1.8.0.

Para as análises dendrométricas foi realizada uma amostragem de $10 \%$ dos números de trechos de cada bairro, devido à irregularidade do tamanho das quadras e consequentemente, dos trechos de calçadas arborizadas com mangueiras, conforme recomenda Andrade (2002). Foram tomadas as medidas de altura total e de circunferência a altura do peito (CAP) de todos os indivíduos com até 1,80 $\mathrm{m}$ de altura da primeira bifurcação nos bairros urbanizados. O CAP foi convertido e diâmetro a altura do peito (DAP) pela seguinte equação:

$$
\mathrm{DAP}=\mathrm{CAP} / \pi
$$

Para a análise da estrutura vertical (altura) e horizontal (diâmetro) dos indivíduos, foram utilizados histogramas de frequência, com intervalos de classes com amplitude de 5,0 e 10,0 cm, respectivamente, atendendo as recomendações de Stepka (2008) e Rode (2008).

Para o cálculo de índices espaciais da arborização de ruas, foram utilizados os seguintes índices: Índice de Mangueira por Quilômetro de Calçada Arborizada (IMQC), Índice de Cobertura Arbórea (ICA) e Índice de Densidade Arbórea (IDA).

O Índice de Árvores por Quilômetro de Calçada Arborizada (IMQC) foi calculado por meio da seguinte equação:

$$
\mathrm{IMQC}=\frac{\mathrm{Nmang}}{\mathrm{TkmCA}}
$$

Em que:

IMQC = Índice de Mangueira por Quilômetro de Calçada Arborizada;

$\mathrm{N}_{\text {Mang }}=$ número de mangueira na população;

$\mathrm{T}_{\mathrm{Km} \mathrm{CA}}=$ total de quilômetros de calçadas arborizadas na população.

De acordo com Lima Neto et. al (2011) o Índice de Cobertura Arbórea (ICA) tem a função de fornecer o percentual de cobertura da arborização nas ruas, dado pela equação:

$$
\mathrm{ICA}=\left[\frac{\sum_{\mathrm{i}=1}^{\mathrm{n}} \mathrm{AC}}{\sum_{\mathrm{i}=1}^{\mathrm{n}} \mathrm{AR}}\right] \mathrm{x} 100
$$




\section{Em que:}

ICA = Índice de Cobertura Arbórea;

$\mathrm{n}$ = número de ruas da amostra;

$A C=$ área de copa das mangueiras $\left(\mathrm{m}^{2}\right)$;

$\mathrm{AR}=$ área da calçada $\left(\mathrm{m}^{2}\right)$.

Lima Neto (2014) afirma que o Índice de Densidade Arbórea (IDA) confere a quantidade de número de indivíduos arbóreos para cada $100 \mathrm{~m}^{2}$ de área da calçada, definido conforme equação:

$$
\mathrm{IDA}=\left[\frac{\mathrm{Na}}{\sum_{\mathrm{i}=0}^{\mathrm{n}} \mathrm{AR}}\right] \mathrm{x} 100
$$

Em que:

IDA = Índice de Densidade Arbórea;

$\mathrm{n}$ = número de ruas da amostra;

$\mathrm{Na}=$ número de árvores na amostra;

$\mathrm{AR}=$ área da calçada $\left(\mathrm{m}^{2}\right)$.

\section{RESULTADOS E DISCUSSÃO}

As médias de altura e diâmetro do tronco das mangueiras nos bairros do Distrito de Belém estão apresentadas na Tabela 1.

A altura média das 239 mangueiras amostradas foi de 11,62 m, com um desvio padrão de 3,36. As maiores alturas foram observadas nos bairros Nazaré e Batista Campos, decorrente do maior espaço disponível no meio urbano. Os baixos valores de desvio padrão se devem a falta de plantio de mangueira nos últimos anos nas ruas de Belém.

$\mathrm{Na}$ figura 4, pode-se observar que a curva gerada pela distribuição das mangueiras em classes de altura assumiu característica unimodal, indicando uma população com grande porte ou uma população mais madura. Para Bobrowski (2011), quando a curva de distribuição tende a ser do tipo unimodal, a população amostrada é mais velha, com indivíduos de maior porte remanescentes associados a indivíduos mais jovens plantados, dando indício do amadurecimento da arborização com moderadas taxas de plantio. 
Tabela 1 - Média e desvio padrão da altura total e diâmetro do tronco de mangueiras localizadas nos bairros do distrito administrativo de Belém (PA).

\begin{tabular}{cccccc}
\hline \multirow{2}{*}{ Bairros } & NMi & \multicolumn{2}{c}{ Htot } & \multicolumn{3}{c}{$\begin{array}{c}\text { Diam. } \\
\text { Tronco }\end{array}$} \\
\cline { 3 - 6 } & & $\overline{\mathbf{x}} \mathbf{( m )}$ & $\mathbf{s}$ & $\overline{\mathbf{x}} \mathbf{( m )}$ & $\mathbf{s}$ \\
\hline Guamá & 1 & 10,00 & 0,00 & 0,45 & 0,00 \\
Cidade Velha & 3 & 10,90 & 0,8 & 0,84 & 0,37 \\
Reduto & 6 & 11,67 & 1,63 & 0,57 & 0,17 \\
Jurunas & 12 & 10,25 & 1,36 & 0,61 & 0,19 \\
Marco & 15 & 10,40 & 3,20 & 0,53 & 0,29 \\
Cremação & 10 & 10,23 & 1,73 & 0,50 & 0,34 \\
Campina & 12 & 11,42 & 1,93 & 0,65 & 0,31 \\
São Brás & 39 & 10,99 & 3,48 & 0,49 & 0,23 \\
Umarizal & 34 & 10,66 & 2,89 & 0,72 & 0,27 \\
Batista Campos & 31 & 13,26 & 4,21 & 0,81 & 0,41 \\
Nazaré & 76 & 12,61 & 3,41 & 0,55 & 0,25 \\
\hline Média & 21,73 & 11,13 & 2,24 & 0,61 & 0,26 \\
\hline
\end{tabular}

Fonte: Os autores (2014)

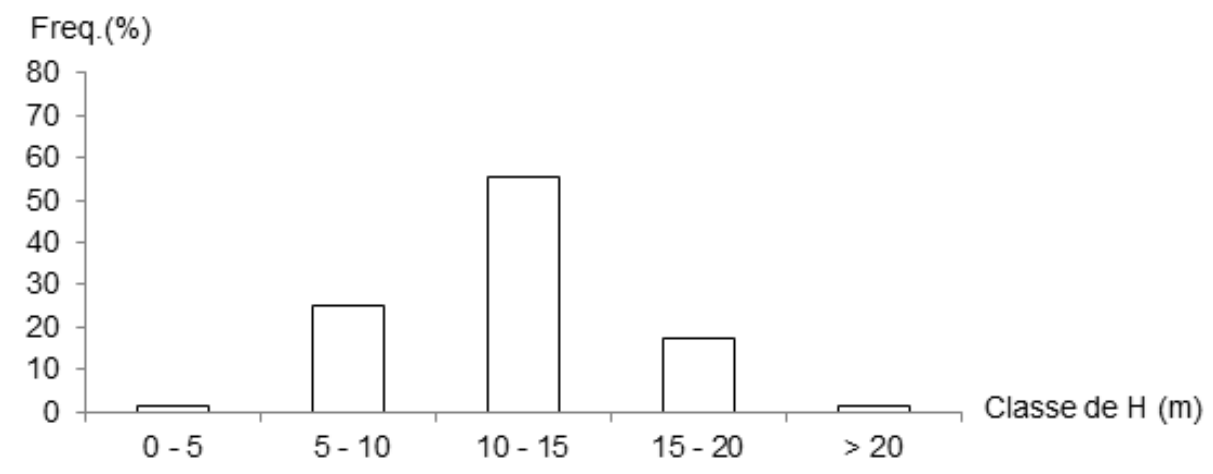

Figura 4 - Distribuição hipsométrica de mangueiras localizadas nos bairros do distrito administrativo de Belém (PA)

Observa - se que $11,03 \%$ e $25,1 \%$ das mangueiras encontram-se nos intervalos de 0 |- 5 e 5 |- $10 \mathrm{~m}$ de altura, respectivamente caracterizando indivíduos que ainda não atingiram a idade adulta. Segundo Bobrowski (2011) isto pode ser um resultado desejável, pois menores são as necessidades de poda de manutenção e condução para diminuir os conflitos gerados entre a expansão da copa e as distâncias de segurança de cada tipo rede.

Nota-se que mais da metade das mangueiras (55,2\%) encontra-se nos intervalos de $10 \mid-15 \mathrm{~m}$ de altura, indicando que essa espécie está em conflito ou 
ultrapassaram a altura da rede aérea. Lima Neto (2014) afirma que esta situação é vista como um risco pelas concessionárias devido aos galhos que encostam ou caem na rede ou mesmo árvores inteiras que caem sobre a rede. Nestes casos torna-se ainda mais importante a avaliação de árvores com risco de queda.

As mangueiras na classe de altura a partir de $15 \mathrm{~m}$ podem ser desejáveis diminuindo os conflitos com a rede de energia, ultrapassando e formando um corredor de área verde. Isto agrega benefícios ambientais diversos; porém também pode ser indesejável por constituir a situação de maior risco de queda gerada por galhos de maior porte.

Nos trabalhos realizados por Almeida e Rondon Neto (2010) nas cidades de Colider e Matupá (MT), e Strangheti e Silva (2010) na cidade de Uchôa (SP), também foram observadas curvas de distribuição unimodal em classes de altura semelhantes para a arborização de ruas estudadas nessas cidades.

Assim, Bobrowski (2011) afirma que a distribuição de classes de altura da arborização é influenciada pelo tipo de poda realizada, principalmente por podas drásticas e de rebaixamento que alteram as características naturais de altura e da forma da copa das árvores.

A média do diâmetro do tronco das mangueiras foi de $0,61 \mathrm{~m}$, com desvio padrão de 0,30. O bairro Cidade Velha foi o que apresentou a maior média de circunferência de tronco, devido à predominância de plantios antigos, enquanto que os diâmetros médios e pequenos foram observados nos bairros, onde os plantios são mais jovens.

Na distribuição das classes diamétricas encontrou-se uma tendência a curva multimodal (vários pontos de máxima frequência), com distinção de dois períodos de plantio de mangueiras (Figura 5).

A metade do século XIX marca o período de plantio mais recente de mangueira nas ruas de Belém. Isto pode ser observado nos intervalos $(0 \mid-10 \mathrm{~cm}, 10$ |- $20 \mathrm{~cm}$ e 30 |- $40 \mathrm{~cm}$ ) com poucos indivíduos jovens, tendo maior concentração nas classes centrais (40 |- $50 \mathrm{~cm}$ e $50 \mid-60 \mathrm{~cm}$ ), indicando uma fase de amadurecimento da espécie nas ruas de Belém. Segundo Bobrowski, Biondi e Figueiredo (2012), isto pode indicar maior concentração de árvores em estágio de maturidade e moderadas taxas de plantios recentes ou reposições, possivelmente devido à falta de espaços 
que compatibilizem a harmonia entre as árvores e as estruturas urbanas, mas também devido a ações de vandalismo que suprimiram árvores.

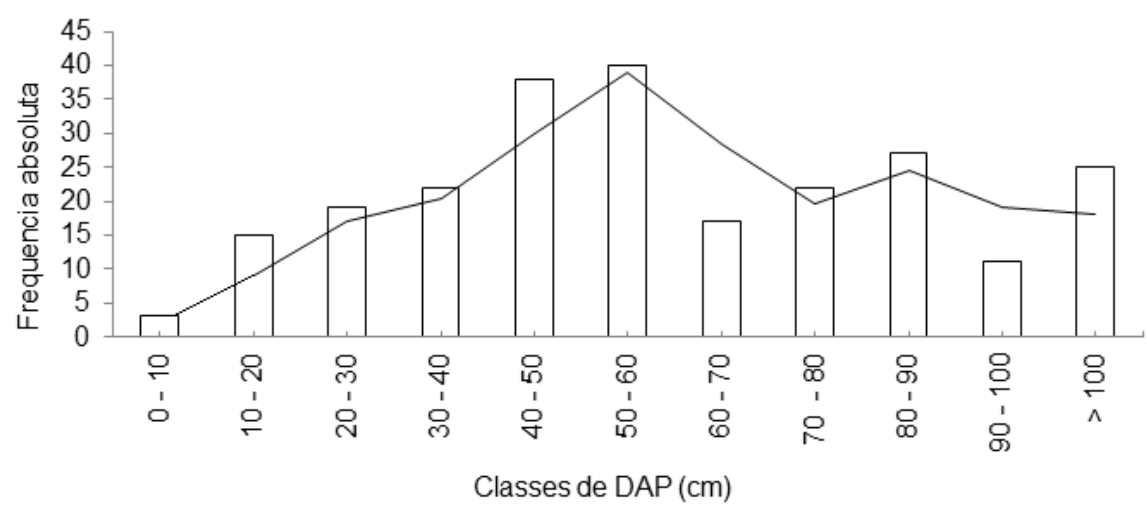

Figura 5 - Distribuição diamétrica de mangueiras localizadas nos bairros do distrito administrativo de Belém (PA).

O segundo período de plantio, fim do século XIX, encontra-se nas faixas de diâmetro que variam de $60-70 \mathrm{~cm}$ a $>100 \mathrm{~cm}$, indicando uma fase de plantios antigos que atingiram a maturidade. Assim, é recomendado o acompanhamento desse plantio mais antigo, por meio de avaliações regulares do risco de queda dessas árvores a fim de evitar tombamentos, problemas com as estruturas urbanas e até ferimentos ou mortes de pessoas.

Scolforo (2006) afirma que as distribuições multimodais apresentam pouca importância nos estudos florestais, podendo existir tanto em florestas naturais como em florestas plantadas, onde pode ser aplicado um sistema de exploração apenas em certas classes diamétricas. Contudo, Lana et al. (2012) ao estudar a estrutura diamétrica da cidade de Parnarama (MA), encontrou uma distribuição diamétrica correspondente à curva de distribuição multimodal.

$\mathrm{Na}$ Figura 6 e Tabela 2 estão apresentadas a distribuição espacial e a quantidade das mangueiras existentes nas calçadas do DABEL, respectivamente.

O maior número de mangueiras foi encontrado no bairro Nazaré, 932 indivíduos $(35,18 \%)$, enquanto que o menor número foi verificado no bairro Guamá, 10 indivíduos, representando $0,38 \%$. Nazaré é um bairro estruturado e tradicional, enquanto que Guamá é o mais populoso da cidade de Belém (PMB, 2012). 


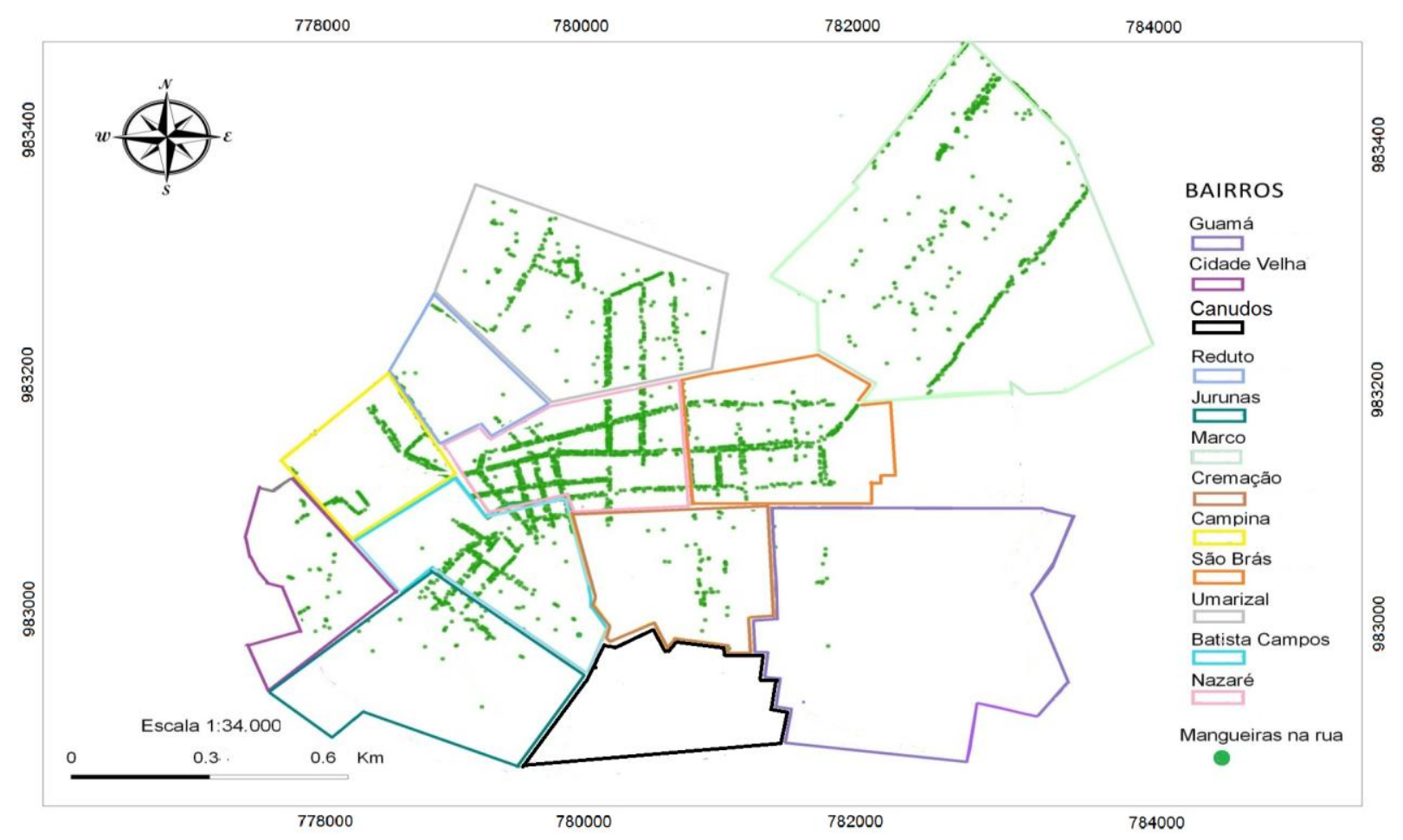

Figura 6 - Espacialização de mangueiras nos bairros do distrito administrativo de Belém (PA).

Tabela 2 - Distribuição quantitativa de mangueiras localizadas nos bairros do distrito administrativo de Belém (PA).

\begin{tabular}{l|c|c|c|c}
\hline Bairros & $\begin{array}{c}\text { № de } \\
\text { mangueiras }\end{array}$ & $\begin{array}{c}\text { Total de calçadas } \\
(\mathrm{km})\end{array}$ & $\begin{array}{c}\mathrm{N} \text { o de } \\
\text { Mangueiras } \\
/ \mathrm{km}\end{array}$ & $\begin{array}{c}\text { Frequência de } \\
\text { mangueiras } \\
(\%)\end{array}$ \\
\hline Guamá & 10 & 53,12 & 0,2 & 0,38 \\
Cidade Velha & 39 & 23,86 & 1,6 & 1,47 \\
Reduto & 79 & 19,82 & 4,0 & 2,98 \\
Jurunas & 98 & 40,29 & 2,4 & 3,70 \\
Marco & 101 & 87,22 & 1,2 & 3,81 \\
Cremação & 108 & 24,99 & 4,3 & 4,08 \\
Campina & 205 & 27,03 & 7,6 & 7,74 \\
São Brás & 334 & 32,47 & 10,3 & 12,61 \\
Umarizal & 348 & 53,17 & 6,5 & 14,91 \\
Batista Campos & 395 & 34,01 & 11,6 & 13,14 \\
Nazaré & 932 & 28,46 & 32,7 & 35,18 \\
\hline Total & 2649 & 424,4 & 82,4 & 100 \\
\hline
\end{tabular}

Fonte: Os autores (2014) 
No Distrito Administrativo de Belém DABEL, em média, encontrou-se sete mangueiras por quilômetro de calçada. Santamour Júnior (1990) considera que para evitar prejuízos com o ataque severo de pragas, a composição de espécies não deve exceder $10 \%$ para a mesma espécie, $20 \%$ para um mesmo gênero e $30 \%$ para uma mesma família botânica. Ressalta- se que essa recomendação é para cidades de clima temperado, onde há uma biodiversidade menor do que em climas tropicais para ser utilizada na arborização urbana. Dessa forma, o bairro de Nazaré $(35,18 \%)$ foi o que apresentou maior percentual de indivíduos de mangueira, caracterizando uma situação não recomendável para a mesma espécie, pois aumenta o risco de perdas. Já os bairros Umarizal (14,91\%), Batista Campos (13,14\%) e São Brás $(12,61 \%)$ estão numa situação de menor risco e os outros bairros abaixo do recomendado por Santamour Júnior (1990).

Comparando estes resultados com cidades que apresentam mangueiras na arborização de ruas, Batista et al. (2013) verificaram em Remígio (PB), 10 espécies $(6,5 \%)$ no levantamento da arborização de ruas, com predominância da espécie de Mangifera indica (3\%). Moura e Santos (2009) constataram menos de 1\% dos indivíduos de mangueira em Várzea Grande (MT). Já em Assis (SP), as mangueiras representam apenas $0,05 \%$ das árvores, mostrando pouca ocorrência da espécie na arborização de ruas (ROSSATO; TSUBOY; FREI, 2008).

$\mathrm{Na}$ Tabela 3 estão apresentados os resultados encontrados para os índices espaciais do DABEL.

O maior índice de número de mangueira por quilômetro de calçada (IMQC) foi encontrado no bairro de Nazaré, representado aproximadamente 32 mangueiras a cada quilômetro de calçada arborizada. Os menores IMQC foram encontrados nos bairros do Guamá $(0,19)$, Marco $(1,16)$ e Cidade Velha $(1,63)$.

$\mathrm{Na}$ cidade de Chapadão do Sul (MS), observou-se um índice de 106,6 árvores por quilômetro de calçada. Pelegrim et al. (2012) obtiveram um índice igual a 0,26 de indivíduos de mangueira por quilômetro de calçada. Dessa forma, verifica-se que em média o índice encontrado neste trabalho, de aproximadamente sete árvores por quilômetro de calçada, é maior do que os obtidos na cidade de Chapadão do Sul - MS. 
Tabela 3 - Índices espaciais da arborização de ruas do distrito administrativo de Belém (PA).

\begin{tabular}{|c|c|c|c|c|c|c|c|}
\hline $\begin{array}{l}\text { Indice } \\
\text { Baikgros }\end{array}$ & Nmang. & $\begin{array}{l}\text { CalçA } \\
(\mathrm{km})\end{array}$ & Actot $\left(\mathrm{m}^{2}\right)$ & Acalç $\left(m^{2}\right)$ & IMQC & ICAcalç & IDA \\
\hline Guamá & 10 & 53,12 & 136,78 & 1680,00 & 0,19 & 0,08 & 0,60 \\
\hline Cidade Velha & 39 & 23,86 & 433,51 & 5395,50 & 1,63 & 0,08 & 0,72 \\
\hline Reduto & 79 & 19,82 & 1463,24 & 13623,70 & 3,99 & 0,17 & 0,58 \\
\hline Jurunas & 98 & 40,29 & 2280,58 & 17806,95 & 2,43 & 0,13 & 0,55 \\
\hline Marco & 101 & 87,22 & 5624,48 & 22168,25 & 1,16 & 0,07 & 0,46 \\
\hline Cremação & 108 & 24,99 & 2283,88 & 17001,00 & 4,32 & 0,19 & 0,64 \\
\hline Campina & 205 & 27,03 & 3255,00 & 17253,70 & 7,58 & 0,33 & 1,19 \\
\hline São Brás & 334 & 32,47 & 14895,58 & 62552,20 & 10,29 & 0,24 & 0,53 \\
\hline Umarizal & 348 & 53,17 & 6706,42 & 59412,10 & 6,55 & 0,12 & 0,59 \\
\hline Batista Campos & 395 & 34,01 & 7269,26 & 70227,35 & 11,61 & 0,10 & 0,56 \\
\hline Nazaré & 932 & 28,46 & 27228,88 & 156360,64 & 32,75 & 0,17 & 0,60 \\
\hline
\end{tabular}

Legenda: CalçA: quilômetro de calçada; NMang: número de mangueiras ; ACtot: área de copa total; Acalç: área total de calçadas arborizadas; IMQC: índice de número de mangueiras por quilometro de calçada; ICAcalç: índice de cobertura arbórea das calçadas arborizadas; IDA: índice de densidade arbórea

Quanto ao índice de cobertura arbórea das calçadas arborizadas (ICA calç), o bairro Campina apresentou o melhor resultado, evidenciando que $33 \%$ de suas calçadas apresentam cobertura com mangueira. Os bairros Jurunas (13\%), Umarizal (12\%), Batista Campos (10\%) Guamá e Cidade Velha com (8\%) e o Marco (7\%) apresentaram índices abaixo do encontrado por Brasil (1994), que foi de 16\% na cidade de Belém.

Os percentuais encontrados nesta pesquisa são referentes aos trechos de ruas arborizados com mangueira e os resultados ajudam a perceber a necessidade de plantio de mangueiras, uma vez que até o encontrado na literatura é considerado baixo e, alguns bairros ainda apresentam percentuais inferiores a esse.

Quanto ao Índice de Densidade Arbórea (IDA), o bairro Campina revelou a maior quantidade de mangueira a cada $100 \mathrm{~m}^{2}$. O bairro do Marco apresentou 0 menor índice $(0,46)$. Este índice é importante, pois indica a intensidade de ocupação das árvores em determinada área. Contudo, deve-se equilibrar a estrutura urbana com os objetivos desejados da arborização, como exemplo, para convivência entre 
as árvores, a rede de distribuição de energia e a localização de postes devem ser próximas ao meio fio a fim de evitar que o alinhamento destes coincida com o das árvores.

No planejamento da arborização urbana de uma cidade, Lima Neto (2014) afirma que se deve levar em consideração a estrutura urbana e equipamentos presentes, tais como: rede aérea, postes de iluminação, redes de esgoto, placas de sinalização, entre outros, pois nem sempre os objetivos da arborização para cada rua são os mesmos.

Loureiro e Barbosa (2010) afirmam que um dos principais objetivos do planejamento do espaço urbano de Belém é resgatar e valorizar a fisionomia e a visualização dos elementos peculiares à cidade, como as mangueiras, tendo os "túneis de mangueiras" como integrantes do conjunto paisagístico e histórico da área central, e como tal, devem ser preservados. Para a formação de túneis de árvores nas ruas, recomenda-se que a projeção da copa das árvores seja maior do que o espaçamento.

\section{CONCLUSÕES}

A estrutura das mangueiras indicou uma arborização com predominância de plantios antigos com uma distribuição espacial de forma bastante heterogênea, podendo ser corrigido através de um melhor planejamento de plantio.

A aplicação dos índices espaciais indicou uma má distribuição de mangueiras nas ruas do DABEL. Portanto, recomenda-se a intensificação de plantios com mangueiras para que as ruas aumentem o percentual de cobertura arbórea do distrito.

\section{Referências}

ALMEIDA, D. N.; RONDON NETO, R. M. Análise da arborização urbana de duas cidades da região norte do Estado de Mato Grosso. Revista Árvore, v. 5, n. 1, p. 899-906, set./ out., 2010. 
ANDRADE, T. O. Inventário e análise da arborização viária da estância turística de Campos do Jordão, SP. São Paulo, 129 f. 2002. Dissertação (Mestrado em Agronomia) - Escola Superior de Agricultura, Universidade de São Paulo.

ANDRADE, V. R. O. Antônio Lemos e as obras de melhoramentos urbanos em Belém: a Praça da República como estudo de caso. Rio de Janeiro, 223f. 2003. Dissertação (Mestrado em Arquitetura) - Universidade Federal do Rio de Janeiro.

BATISTA, F. A.; CHAVES, T. P.; FELISMINO, D.C.; DANTAS, I.C. Inventário qualiquantitativo da arborização urbana na cidade de Remígio, Paraíba. Revista de Biologia e Farmácia, v.9, n.1, p. 70 - 83, mar./mai., 2013.

BOBROWSKI, R. Estrutura e dinâmica da arborização de ruas de Curitiba, Paraná, no período 1984 - 2010. Curitiba, 144f. 2011. Dissertação (Mestrado em Engenharia Florestal) - Setor de Ciências Agrárias, Universidade Federal do Paraná.

BOBROWSKI, R.; BIONDI, D.; FIGUEIREDO, A. F. Dinâmica da distribuição diamétrica na arborização de ruas da cidade de Curitiba, Paraná, Brasil. Scientia Forestalis, v. 18, n. 1, p. 167 - 178, jun., 2012.

BRASIL, H. M. S. Belém, eterna cidade das mangueiras. Disponível em: <http://www.orm.com.br/projetos/oliberal/interna/?modulo=247\&codigo=626133 >. Acessado em 17/01/2013.

BRASIL, H. M. S. Caracterização de arborização urbana: o caso de Belém. Belém, 204 f. 1994. Dissertação (Mestrado em Ciências Biológicas) - Universidade Federal do Pará.

GUSMÃO, L. H. A. O avanço da verticalização em Belém. Geocartografia digital. Disponível em: <http://geocartografiadigital.com.br>. Acessado em: 12/11/2014.

INSTITUTO DE DESENVOLVIMENTO ECONÔMICO, SOCIAL E AMBIENTAL DO PARÁ (IDESP). Estatística municipal. Disponível em: $<$ http://iah.iec.pa.gov.br/iah/fulltext/georeferenciamento/belem.pdf>. Acessado em: 06/09/2013.

LANA, M. D.; SILVA, O. C. F. L. B.; MILANI, J. E. F.; BRAZ, E. M.; MOGNON, F. Estrutura diamétrica e altimétrica de duas áreas de cerrado, localizadas em Parnarama, Maranhão - Brasil. In Congresso Florestal Estadual, 2., 2012; Rio Grande do Sul. Anais... Rio Grande do Sul : CFE, 2012. p. 21 - 25.

LIMA NETO, E. M. Índices e métricas para a gestão das árvores de rua de Boa Vista - RR a partir de cadastro espacial. Curitiba, $169 \mathrm{f}$. Tese (Doutorado em Engenharia Florestal) - Setor de Ciências Agrárias, Departamento de Universidade Federal do Paraná.

LIMA NETO, E. M.; BIONDI. D.; MARTINI, A.; BOBROWSKI, R. O uso de Sistema de Informação Geográfica para o Índice de Cobertura Arbórea (ICA) em ruas de 
Curitiba-Brasil. In: CONGRESSO FLORESTAL LATINO AMERICANO, 2., 2011, Lima - Peru. Anais... Lima - Peru: CONFLAT, 2011. p. 3-12.

LORENZI, H.; BACHER, L.; LACERDA, M.; SARTORI, S. Frutas brasileiras e exóticas cultivadas: de consumo in natura. São Paulo: instituto Plantarium de Estudos da Flora, 2006. 640p.

LOUREIRO, V. R.; BARBOSA, E. J. S. Cidade de Belém e natureza: uma relação problemática?. Periódicos UFPA, v.13, n.1, p. 105- 134, mar./mai., 2010.

LUZ, L. M.; RODRIGUES, J. E. C. Análise do índice da cobertura vegetal em áreas urbanas: estudo de caso da cidade de Belém - PA. Boletim Amazônico de Geografia. http://www.boletimamazonicodegeografia.ufpa.br/index.php/revista/article/view/15 > Acessado em: 14/10/2013.

MACO, S. E.; MCPHERSON, E. G. A practical approach to assessing structure, function, and value of street tree populations in small communities. Journal of Arboriculture, v. 29, n 2, p. 84-97, fev./ mar., 2003.

MOURA, T. A.; SANTOS, V. L. L. V. Levantamento quali-quantitativo de espécies arbóreas e arbustivas na arborização viária urbana dos bairros centro e centro norte, Várzea Grande, Mato Grosso, Brasil. Revista da Sociedade Brasileira de Arborização Urbana, v.1, n.1, p. 97-117, 2009.

NASCIMENTO, M.; AGUIAR, R.; MOUTINHO, T. Cidade de Belém. Disponível em: <http://www.ufra.edu.br/econpet2010/belem.html>. Acessado em 14/04/2013.

PELEGRIM, E. A. L.; LIMA, A. P. L.; LIMA S, F. Avaliação qualitativa e quantitativa da arborização no bairro Flamboyant em Chapadão do Sul, MS. Revista Brasileira de Arborização Urbana, v.7, n.1, p. 126 - 142, 2012.

PREFEITURA MUNICIPAL DE BELÉM (PMB). Anuário estatístico do município. 2013. Disponível em: $<$ http://www.belem.pa.gov.br/app/c2ms/v/?id=2\&conteudo=4485>. Acessado em 29/06/2013.

RODE, R. Avaliação florística e estrutural de uma floresta ombrófila mista e de uma vegetação arbórea estabelecida sob um povoamento de Araucaria angustifolia de 60 anos. Curitiba, 2008. 159 f. Dissertação (Mestrado em Engenharia Florestal) - Setor de Ciências Agrárias, Universidade Federal do Paraná.

ROSSATO, D. R.; TSUBOY, M. S. F.; FREI, F. Arborização urbana na cidade de Assis - SP: uma abordagem quantitativa. Revista Sociedade Brasileira de Arborização Urbana, v.3. n.1, p. 1-16, 2008.

SANTAMOUR JÚNIOR, F. S. Trees for urban planting: diversity, uniformity, and common sense. In: Proceedings of Metria Conference; 1990; Lisle: Metria; 1990 p.57 - 66 . 
SCOLFORO, J. R. S. Biometria florestal: Modelos de crescimento e produção florestal. Lavras: Editora: UFLA/FAEPE; 2006.

SILVA, L. M. G. Doses e métodos de aplicação do paclobutrazol em mangueiras cv. Tommy Atkins. Cruz das Almas, Bahia, 57 f. 2000. Dissertação (Mestrado em Agronomia) - Escola de Administração, Universidade Federal da Bahia.

STEPKA, T. F. Modelagem da dinâmica e prognose da estrutura diamétrica de uma Floresta Ombrófila Mista por meio de matriz de transição e razão de movimentação. Irati, 138 f. 2008. Dissertação (Doutorado em Ciências florestais) Departamento da Universidade Estadual do Centro - Oeste.

STRANGHETI V, SILVA, Z. A. V. Diagnóstico da arborização das vias públicas do município de Uchoa-SP. Revista da Sociedade Brasileira de Arborização Urbana, v. 5, n.2, p. $124-138,2010$. 